\title{
Deletion of rapQONML from the Rapamycin Gene Cluster of Streptomyces hygroscopicus
}

\section{Gives Production of the 16-O-Desmethyl-27-desmethoxy Analog}

\author{
Loleta Chung, Lu Liu ${ }^{\dagger}$, Sejal Patel ${ }^{\dagger \dagger}$, John R. Carney \\ and Christopher D. Reeves* \\ Kosan Biosciences, Inc., \\ 3832 Bay Center Place, Hayward, CA 94545, U.S.A.
}

(Received for publication September 13, 2000)

\begin{abstract}
Five contiguous genes in the rapamycin gene cluster, rapQONML, of Streptomyces hygroscopicus ATCC29253 were replaced with a neomycin resistance marker by double homologous recombination. The resulting strain, if fed pipecolate, produced the analog 16-Odesmethyl-27-desmethoxyrapamycin instead of rapamycin. This indicates that the $\mathrm{P} 450$ hydroxylase encoded by rap $N$ is specific for $\mathrm{C}-27$, and that the $O$-methyltransferases encoded by rapQ and rapM methylate the hydroxyl groups on $\mathrm{C}-16$ and $\mathrm{C}-27$. By inference, the remaining $\mathrm{P} 450$ hydroxylase and methyltransferase genes (rapI and rapJ) are responsible for hydroxylation of C-9 and methylation of the C-39 hydroxyl, consistent with their homology to $f k b D$ and $f k b M$, respectively, in the FK506 cluster. The relatively high level of 16-O-desmethyl27-desmethoxyrapamycin produced indicates that the reactions at C-9 and C-39 do not require previous modification of the macrolactone precursor at either $\mathrm{C}-16$ or $\mathrm{C}-27$.
\end{abstract}

Rapamycin was originally discovered as an antifungal agent from Streptomyces hygroscopicus ATCC 29253 $3^{1)}$ and later found to be an immunosuppressant with a unique mechanism of action (sirolimus, Rapamune ${ }^{\mathrm{TM}}$ ). Its structural complexity precludes many chemical modifications that might provide new drug candidates. Because rapamycin biosynthesis involves a modular polyketide synthase (PKS) system ${ }^{2)}$, genetic engineering can be used to obtain analogs not previously available ${ }^{3)}$.

Analysis of a $100 \mathrm{~kb}$ region of the $S$. hygroscopicus genome encompassing the rapamycin biosynthetic gene cluster $^{2,4,5)}$ revealed five genes immediately downstream of rap $C$ putatively encoding an $O$-methyltransferase $(\operatorname{rap} Q)$, a ferredoxin $(r a p O)$, a $\mathrm{P} 450$ hydroxylase $(\operatorname{rapN})$, a second $O$ methyltransferase (rapM) and lysine cyclodeaminase (rapL). The rapL gene was proven to encode the activity needed to convert lysine into pipecolic $\operatorname{acid}^{6)}$, the final unit incorporated into the macrolactone precursor. A second $\mathrm{P} 450$ hydroxylase gene (rapJ) and a third $O$ methyltransferase gene (rap $)$ are closest in sequence to $f k b D$ and $f k b M$, which hydroxylate C-9 and methylate the 31-hydroxyl group of the dihydroxycyclohexane ring, respectively, of FK506 $6^{7,8)}$. Results from isotope labeling ${ }^{9,10)}$ and other studies ${ }^{11)}$ suggest that the PKS product and its subsequent modification is as shown in Fig. 1. The PKS complex synthesizes a 31-member macrolactone precursor, starting with a shikimate-derived unit and ending with a pipecolate unit incorporated by a non-ribosomal peptide synthetase module. The precursor is hydroxylated at C-9 and $\mathrm{C}-27$, the 16-, 27- and 39-hydroxyl groups are methylated, and the 9-hydroxyl group is oxidized to form the $\alpha$-ketoamide. The order in which these post-PKS reactions occur is not known, nor has each reaction been assigned to a specific gene or set of genes.

Here we describe construction and analysis of a strain in which the five genes, $\operatorname{rap} Q O N M L$, were replaced with a neomycin resistance marker. Cultures of this strain, if fed pipecolate, produced significant levels of 16-O-desmethyl27-desmethoxyrapamycin. This helps to define the regiospecificities of the two $\mathbf{P} 450$ hydroxylases and the

\footnotetext{
Present addresses: ${ }^{\dagger}$ Maxygen Corporation, 515 Galveston Drive, Redwood City, CA 94063.

${ }^{\dagger+}$ Massachusetts Institute of Technology, 77 Massachusetts Ave, Cambridge, MA 02139.

* Corresponding: reeves@kosan.com
} 
Fig. 1. Post-PKS modifications of the presumed macrolactone precursor of rapamycin.

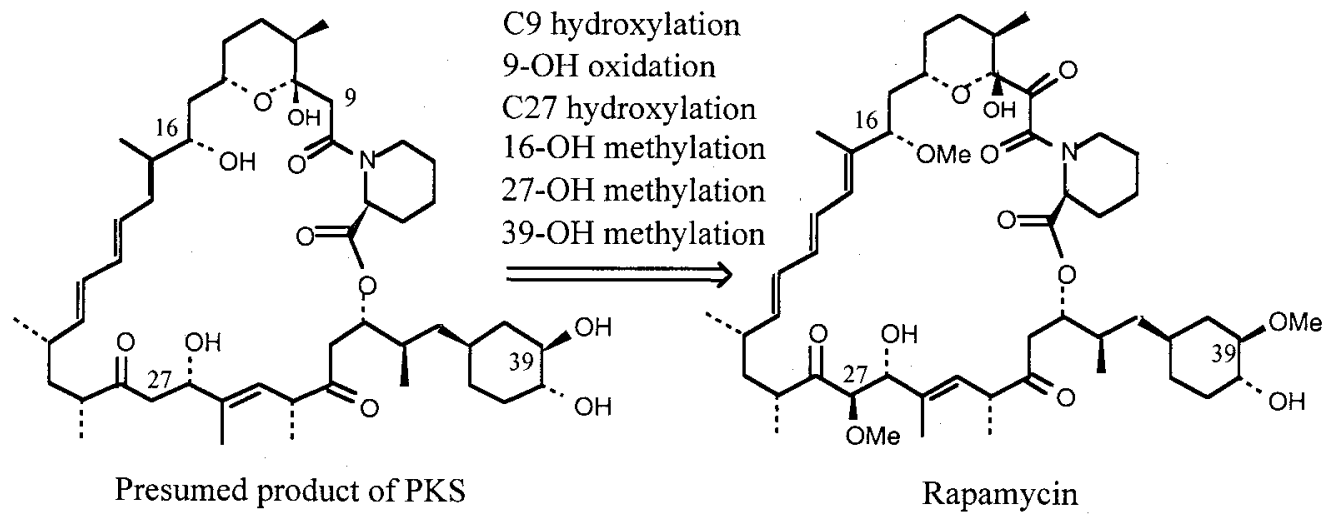

The modification reactions are listed in an arbitrary order. Except that the 9-hydroxylation must occur before the 9-hydroxyl oxidation, the temporal order of these reactions is not known and may not be constrained.

three $O$-methyltransferases.

\section{Materials and Methods}

Bacterial Strains, Plasmids and Phages

Plasmid pFDNEO-S was a kind gift of Prof. RYSZARD BrzezINSKI of the Université de Sherbrooke, Canada. S. hygroscopicus ATCC 29253 and derived strains were plated on SY ( $1 \%$ soluble starch, $0.2 \%$ yeast extract, $20 \%$ agar) to obtain spores. The phage vector KC515 was obtained from the John Innes Centre and was propagated in S. lividans TK24. Vector construction was done in the Escherichia coli strain XL1-Blue from Stratagene.

\section{Assembly of the rapQONML Deletion Cassette}

The cassette for replacement of $\operatorname{rap} Q O N M L$ with a neomycin resistance gene was constructed as shown in Fig. 2. Approximately $1.2 \mathrm{~kb}$ regions upstream and downstream of the rapQONML genes were obtained by PCR amplification from $S$. hygroscopicus genomic DNA. The location of each primer on the published rapamycin cluster sequence $^{2,4,5)}$ given below refers to the $3^{\prime}$ end of each primer. The upstream region was obtained with primers from nucleotide 89986 (5'-ATCGGATCCGCGCCAGGTCCGGCGACCCGTCCGCTTCC-3'), introducing a BamHI site, and 91124 (5'-GATAGATCTAGACCGAAGGCCGACATCACGGTGTCGAAC-3'), introducing a $B g l$ II site. The downstream region was obtained with primers from 95072 (5'-ATCAAGCTTGCTTGATGTCACGCTGGCAC-
AGAACCTTGG-3'), introducing a HindIII site, and 96218 (5'-GATATGCATCCGTGCCGTCCCAGGTTCTCGGCACCGATC-3'), introducing an Nsil site. The PCR mixes included cloned $P f u$ polymerase (Stratagene), the manufacturer's buffer, $10 \%$ DMSO, $200 \mu \mathrm{M}$ each of dATP, dTTP, dCTP, and $100 \mu \mathrm{M}$ each of dGTP and deaza-dGTP (Roche). Thirty cycles of 30 seconds at $95^{\circ}, 30$ seconds at $60^{\circ}$, and 3 minutes at $72^{\circ}$ were used. Each PCR product was cloned into the $\operatorname{Srf}$ I site of pCR-Script (Stratagene) to give pKOS20-55.2 and pKOS20-56.1, respectively, and clones were verified by sequencing.

pKOS7-150 was derived from Litmus 28 and has the following sequence between the SnaB I and Avr II sites: 5'TGGATCCACAGATCTGCCTGCAGCATCTAGAAAGCTTACATGCATCCTAG-3' . The left region was isolated from pKOS20-56.1 as a $1.2 \mathrm{~kb} E c o R I-B g l I I$ fragment and cloned into the EcoRI-BamHI sites of pFDNEO-S ${ }^{12)}$, to give pKOS20-68. The right region was isolated from pKOS20-56.1 as a $1.2 \mathrm{~kb} H i n \mathrm{dIII}-N_{s i} \mathrm{I}$ fragment and cloned into the same sites of pKOS7-150 to give pKOS2061.1. The $2.2 \mathrm{~kb} \mathrm{BamHI-HindIII} \mathrm{fragment} \mathrm{of} \mathrm{pKOS20-68}$ was moved into the same sites of pKOS20-61.1 to give pKOS20-70, in which the neomycin resistance gene was inserted between the rapQONML flanking sequences.

\section{Isolation of a rapQONML Replacement Strain}

The cassette described above was isolated from pKOS2070 as a $3.4 \mathrm{~kb} B a m \mathrm{HI}-N_{s i} \mathrm{I}$ fragment and ligated to the BamHI-PstI sites of KC515 DNA and the DNA transfected into $S$. lividans TK24 protoplasts as 
described ${ }^{13)}$. Recombinant phage plaques were identified using PCR. Phage harboring the replacement cassette was mixed with freshly germinated spores of ATCC 29253 and plated onto modified oatmeal agar $\left(10^{7} \sim 10^{8}\right.$ spores per plate; MOI of $5 \sim 10$ ) as described ${ }^{14)}$. After 20 hours at $30^{\circ} \mathrm{C}$, plates were overlayed with neomycin $(10 \mu \mathrm{g} / \mathrm{ml}$ final concentration) and incubated about 10 days. Selected colonies were transferred to minimal medium containing 20 $\mu \mathrm{g} / \mathrm{ml}$ neomycin and those that grew well after about 10 days were streaked on minimal medium containing 20 $\mu \mathrm{g} / \mathrm{ml}$ neomycin to obtain pure clones. Clones were tested for the double crossover event by patching to medium with neomycin alone and neomycin plus thiostrepton. Selected $\mathrm{Neo}^{\mathrm{R}}$, Thio ${ }^{\mathrm{S}}$ strains were grown in Difco tryptic soy broth supplemented with $1 \%$ glucose, $100 \mathrm{~mm}$ MES (2- $(N-$ morpholino)-ethane sulfonic acid) buffer, $\mathrm{pH} 6.0$ and DNA was isolated as described ${ }^{13)}$. The DNA was analyzed by PCR for the presence of amplimers diagnostic of the double crossover replacement event. The primer pairs annealed to regions outside the left homologous sequence (5'-CGGGCGTCTGATCGACCAGGATGAGATGGG-3') and within the neo cassette promoter (5'-TATGTTGGTGTCATTCTACCAGAATCGGCAAAAGATGTCA-3'), or outside the right homologous sequence (5'-GCGAGGGCGTAGCCCCGGCG-3' $3^{\prime}$ and in the polylinker at the $3^{\prime}$ end of the neo cassette (5'-GTCGACCTGCAGGCATGCAAGCTT$\left.3^{\prime}\right)$. A strain in which the rapQONML region was correctly replaced by the neo cassette was designated KOS20-001.

\section{Fermentation and Analysis of Products}

Spores of S. hygroscopicus ATCC 29253 and KOS20001 were inoculated into $40 \mathrm{ml}$ of supplemented $\mathrm{TSB}^{6)}$ in $250 \mathrm{ml}$ baffled flasks. After 20 hours, cultures were harvested, resuspended in 30\% glycerol and dispensed into $1 \mathrm{ml}$ aliquots to give a working cell bank. One frozen cell vial was used to inoculate $40 \mathrm{ml}$ of supplemented $\mathrm{TSB}^{6}$ in $250 \mathrm{ml}$ baffled flasks. At about 20 hours, the concentration of glucose approached zero, as measured with a YSI 2700 Select biochemistry analyzer, at which time D,L-pipecolate (Sigma) was added to the KOS20-001 cultures $(1 \mathrm{mg} / \mathrm{ml}$ final concentration). Aliquots of the cultures were extracted after $3 \sim 4$ days (when fully grown) as follows. To an aliquot of whole broth two volumes of acetone were added and the mixture was sonicated one minute on ice with a sonic dismembranator 60 (Fisher) set at maximum. Three volumes of ethyl acetate was added, relative to the original aliquot, and the mixture was shaken. After centrifugation, the upper ethyl acetate phase was transferred to a new container, dried by adding anhydrous sodium sulfate, and concentrated by rotary evaporation. The residue was redissolved in ethyl acetate for analysis $(0.5 \%$ of the original broth volume).

Extracts were analyzed using a system comprised of a Beckman System Gold HPLC, an Alltech ELSD detector, and a PE SCIEX API100LC MS-based detector equipped with an atmospheric pressure chemical ionization source. The eluent of a Metachem Inertsil ODS- 3 column $(5 \mu \mathrm{m}$, $4.6 \times 150 \mathrm{~mm}$ ) at $50^{\circ} \mathrm{C}$ of a linear gradient from $50 \%$ to $100 \% \mathrm{MeCN}(0.1 \% \mathrm{HOAc})$ at $1 \mathrm{ml} /$ minute over 5 minutes was monitored by UV at $287 \mathrm{~nm}$, ELSD, and MS. Under these conditions, rapamycin eluted at 9.4 minutes and $16-O$ desmethyl-27-desmethoxyrapamycin at 8.4 minutes. High resolution LC/MS and flow injection MS analysis of a purified sample of 16-O-desmethyl-27-desmethoxyrapamycin was obtained on a PE Biosystems Mariner API-TOF MS configured with an atmospheric pressure chemical ionization or electrospray source, respectively.

KOS20-001 was cultured in a 10-liter fermenter of supplemented TSB medium seeded with a 2-day old $500 \mathrm{ml}$ culture of the same medium. At 3 days, the culture was harvested, an equal volume of methanol was added, and after 30 minutes the suspension was centrifuged. The supernatant was subjected to solid-phase extraction on HP$20(500 \mathrm{ml}$ column volume, $100 \mathrm{ml} /$ minute $)$. After capture, the column was washed with 2 liters of $\mathrm{MeOH}-\mathrm{H}_{2} \mathrm{O}(1: 1)$, followed by 2 liters of $\mathrm{MeOH}-\mathrm{H}_{2} \mathrm{O}(2: 1)$. The new metabolite was then eluted from the column with 1.5 liters of $\mathrm{MeOH}$. A 1-gram portion of the resulting $2.5 \mathrm{~g}$ of residue was fractionated over $\mathrm{LH}-20\left(\mathrm{CH}_{2} \mathrm{Cl}_{2}-\mathrm{MeOH}\right.$, $1: 1)$. Fractions containing the analog were pooled and rechromatographed over LH-20 (heptane - dichloromethane EtOH, 10:10:1). Final purification was by HPLC (10× $250 \mathrm{~mm}$, Metachem Inertsil ODS-3, linear gradient from $50 \% \mathrm{MeCN}-\mathrm{H}_{2} \mathrm{O}$ to $95 \% \mathrm{MeCN}_{-} \mathrm{H}_{2} \mathrm{O}$ over 30 minutes, 5 $\mathrm{ml} /$ minute, $\mathrm{UV}=287 \mathrm{~nm}$ ).

\section{Results and Discussion}

\section{Deletion of the rapQONML Region}

A strain in which the rapQONML region was replaced with a neomycin resistance cassette was constructed as diagrammed in Fig. 2. Sequences flanking the $\operatorname{rap} Q O N M L$ region were cloned by PCR (Fig. 2A), the Tn 5 neomycin resistance cassette of pFDNEO-S was inserted between them, and the cassette was ligated into the KC515 phage vector. The recombinant phage was used to obtain $\mathrm{Neo}^{\mathrm{R}}$ lysogens of $S$. hygroscopicus, which were screened for the double crossover event by patching to agar medium containing both neomycin and thiostrepton. $\mathrm{Neo}^{\mathrm{R}}$, Thio ${ }^{\mathrm{S}}$ 
Fig. 2. Construction of the rapQONML deletion strain.

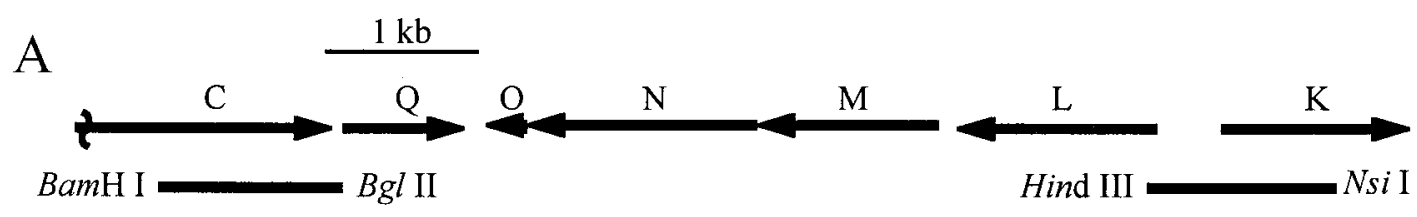

B

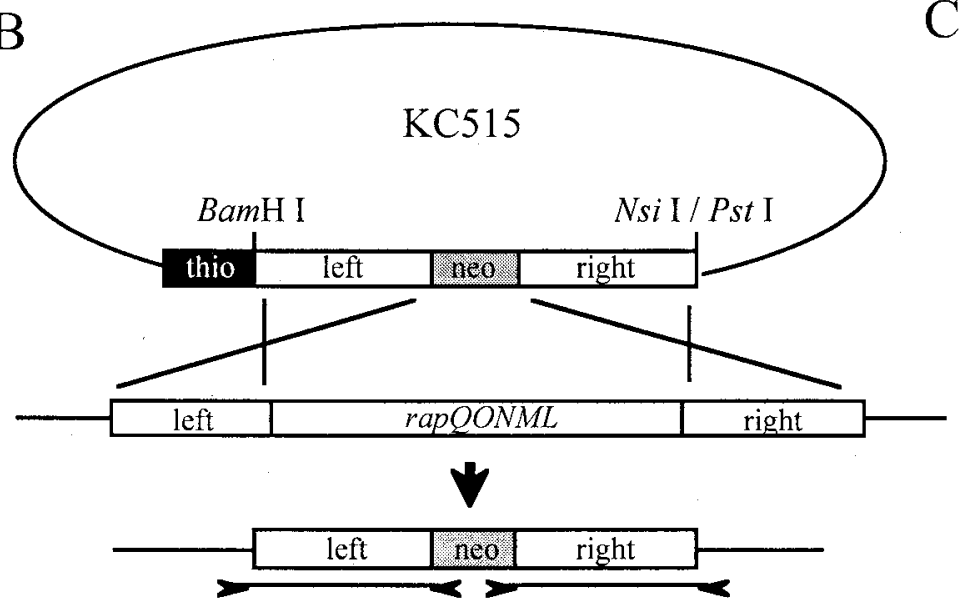

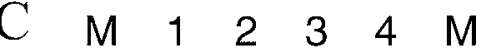

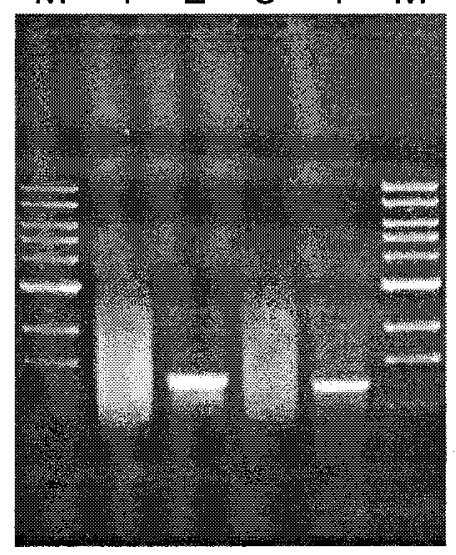

Panel A shows the rapQONML region and the location of the two flanking sequences used in the construction. Panel B diagrams the result of the double crossover event with the recombinant phage DNA; the location of the two amplimers used to verify the double crossover strain is indicated by lines between convergent arrows representing the primers. Panel C shows the results of the PCR reactions with DNA from wild type (lanes 1 and 3) and KOS20-001 (lanes 2 and 4). The primers amplified the left region (lanes 1 and 2) or the right region (lanes 3 and 4 ). The marker lanes $(\mathrm{M})$ are New England Biolabs $1 \mathrm{~kb}$ ladder.

strains were analyzed by PCR using a primer sitting outside each crossover junction paired with a primer within the neomycin resistance gene. DNA from strain KOS20-001 gave both PCR products, which should only be possible if the rapQONML genes are replaced by the neo marker (Fig. $2 \mathrm{~B}$ and $\mathrm{C}$ ).

\section{Characterization of Metabolites Produced by the Deletion Strain}

The engineered (KOS20-001) and wild-type (ATCC 29253 ) strains were fermented in the presence or absence of $1 \mathrm{mg} /$ liter D,L-pipecolate, and the cultures were analyzed as described in Materials and Methods. HPLC-MS showed that the deletion strain, when grown in the presence of pipecolate, produced no detectable rapamycin, but instead produced a new metabolite also with a strong absorption at $287 \mathrm{~nm}$. Comparison of the mass spectrum of rapamycin with that of the new metabolite showed fragmentation that was consistent with 16-O-desmethyl-27-desmethoxyrapamycin (Table 1). By analogy to the series of losses of $2 \mathrm{MeOHs}$ and $2 \mathrm{H}_{2} \mathrm{Os}$ observed for rapamycin, the mass spectra of 16-O-desmethyl-27-desmethoxyrapamycin showed sequential loss of $4 \mathrm{H}_{2} \mathrm{Os}$. As shown in Fig. 3, both compounds displayed loss of fragment $\mathrm{Y}$ and fragments derived from it, indicating that this portion of the molecule was not changed. Fragment $\mathrm{X}$ is also consistent with the proposed structure.

KOS20-001 was cultured in a 10-liter fermenter to provide enough material for further characterization. 16- $O$ Desmethyl-27-desmethoxyrapamycin was isolated from the fermentation broth as described in Materials and Methods. Partial NMR assignments were made from a series of $1 \mathrm{D}$ and TOCSY, HSQC, and HMBC experiments (Table 2). As anticipated, the ${ }^{1} \mathrm{H}$ NMR spectrum of 16-O-desmethyl-27desmethoxyrapamycin displayed only one major methoxy signal at $\delta 3.41$ and the HSQC data showed that these protons were attached to a carbon resonating at $\delta$ 56.4. An 
Table 1. Comparsion of ion masses observed by LC-MS for 16-O-desmethyl-27-desmethoxyrapamycin and authentic rapamycin.

\begin{tabular}{|c|c|c|c|c|c|}
\hline \multicolumn{3}{|c|}{ 16-O-desmethyl-27-desmethoxyrapamycin } & \multicolumn{3}{|l|}{ rapamycin } \\
\hline & calculated & observed & & calculated & observed \\
\hline $\mathrm{C}_{49} \mathrm{H}_{75} \mathrm{NO}_{12} \mathrm{Na}[\mathrm{M}+\mathrm{Na}]^{+}$ & 892.518 & 892.5205 & & & \\
\hline $\mathrm{C}_{49} \mathrm{H}_{76} \mathrm{NO}_{12}[\mathrm{M}+\mathrm{H}]^{+}$ & 870.5368 & not seen & $\mathrm{C}_{51} \mathrm{H}_{80} \mathrm{NO}_{13}[\mathrm{M}+\mathrm{H}]^{+}$ & 914.5630 & not seen \\
\hline $\mathrm{C}_{49} \mathrm{H}_{74} \mathrm{NO}_{11}\left[\mathrm{M}+\mathrm{H}-\mathrm{H}_{2} \mathrm{O}\right]^{+}$ & 852.5262 & 852.5256 & $\mathrm{C}_{50} \mathrm{H}_{76} \mathrm{NO}_{12}\left[\mathrm{M}+\mathrm{H}-\mathrm{CH}_{3} \mathrm{OH}\right]^{+}$ & 882.5368 & 883 \\
\hline $\mathrm{C}_{49} \mathrm{H}_{72} \mathrm{NO}_{10}\left[\mathrm{M}+\mathrm{H}-2 \mathrm{H}_{2} \mathrm{O}\right]^{+}$ & 834.5156 & 834.523 & $\mathrm{C}_{50} \mathrm{H}_{74} \mathrm{NO}_{11}\left[\mathrm{M}+\mathrm{H}-\mathrm{H}_{2} \mathrm{O}-\mathrm{CH}_{3} \mathrm{OH}\right]^{+}$ & 864.5262 & 865 \\
\hline $\mathrm{C}_{49} \mathrm{H}_{70} \mathrm{NO}_{9}\left[\mathrm{M}+\mathrm{H}-3 \mathrm{H}_{2} \mathrm{O}\right]^{+}$ & 816.5051 & 816.511 & $\mathrm{C}_{50} \mathrm{H}_{72} \mathrm{NO}_{10}\left[\mathrm{M}+\mathrm{H}-\mathrm{CH}_{3} \mathrm{OH}-2 \mathrm{H}_{2} \mathrm{O}\right]^{+}$ & 846.5156 & 847 \\
\hline $\mathrm{C}_{49} \mathrm{H}_{68} \mathrm{NO}_{8}\left[\mathrm{M}+\mathrm{H}-4 \mathrm{H}_{2} \mathrm{O}\right]^{+}$ & 798.4945 & 798.511 & $\mathrm{C}_{49} \mathrm{H}_{68} \mathrm{NO}_{9}\left[\mathrm{M}+\mathrm{H}-2 \mathrm{CH}_{3} \mathrm{OH}-2 \mathrm{H}_{2} \mathrm{O}\right]^{+}$ & 814.4894 & 815 \\
\hline $\mathrm{C}_{30} \mathrm{H}_{42} \mathrm{NO}_{6}[\text { Frag. X] }]^{+}$ & 512.3012 & 512.3007 & & & \\
\hline $\mathrm{C}_{19} \mathrm{H}_{31} \mathrm{O}_{4}$ [Frag. Y] ${ }^{+}$ & 323.2222 & 323 & $\mathrm{C}_{19} \mathrm{H}_{31} \mathrm{O}_{4}$ [Frag. Y] & 323.2222 & 323 \\
\hline $\mathrm{C}_{19} \mathrm{H}_{29} \mathrm{O}_{3}\left[\text { Frag. Y }-\mathrm{H}_{2} \mathrm{O}\right]^{+}$ & 305.2117 & 305.2111 & $\mathrm{C}_{19} \mathrm{H}_{29} \mathrm{O}_{3}$ [Frag. Y- $\left.\mathrm{H}_{2} \mathrm{O}\right]^{+}$ & 305.2117 & 305 \\
\hline $\mathrm{C}_{18} \mathrm{H}_{25} \mathrm{O}_{2}$ [Frag. $\left.\mathrm{Y}-\mathrm{H}_{2} \mathrm{O}-\mathrm{MeOH}\right]^{+}$ & 273.1855 & 273 & $\mathrm{C}_{18} \mathrm{H}_{25} \mathrm{O}_{2}$ [Frag. $\left.\mathrm{Y}-\mathrm{H}_{2} \mathrm{O}-\mathrm{MeOH}\right]^{+}$ & 273.1855 & 273 \\
\hline
\end{tabular}

Fig. 3. Fragmentation of 16-O-desmethyl27-desmethoxyrapamycin observed by mass spectrometry.

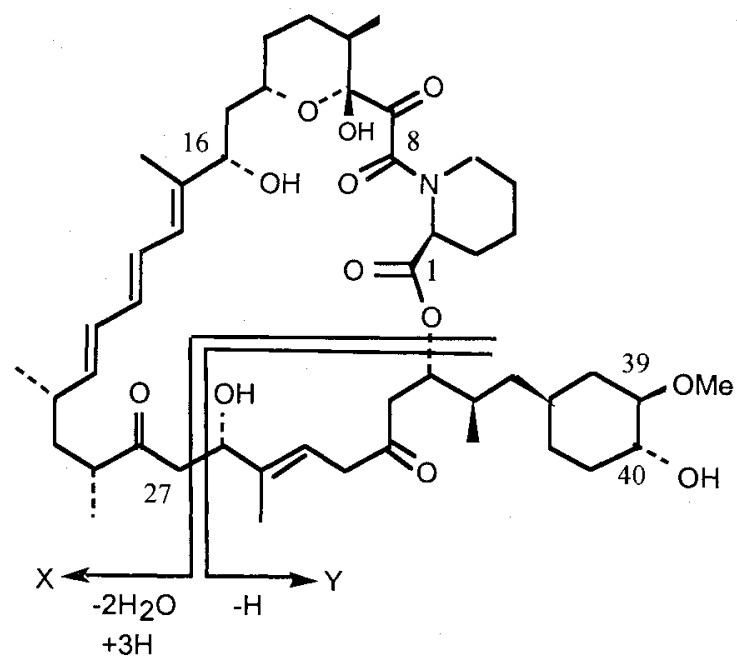

Fragment masses observed for rapamycin and the analog are listed in Table 2.
HMBC cross peak connected the methoxy function to a carbon with a signal at $\delta 84.4$ (C-39). A TOCSY correlation was observed between H-39 (2.93) and a signal at $\delta 3.38$ (H-40), which provided further proof of the location of the methoxy group. These values are in good agreement with those reported for rapamycin ${ }^{15)}$.

Evidence that the new metabolite differed from rapamycin at the 27 -position was provided by the ${ }^{1} \mathrm{H}$ NMR spectrum. The region of $\delta 3.65 \sim 3.75$, where $\mathrm{H}-27$ of rapamycin resonates, was devoid of any signals, and two sets of unique signals at $\delta 2.63(\mathrm{dd}, 17.5,9.5 \mathrm{~Hz})$ and 2.47 (dd, $17.5,3.0 \mathrm{~Hz}$ ), similar to those previously reported for $\mathrm{H}_{2}-27$ of 27-desmethoxyrapamycin ${ }^{16)}$, were observed. In combination, the data indicate that the deletion strain produces the new metabolite 16-O-desmethyl-27desmethoxyrapamycin.

Inferences Regarding Rapamycin Biosynthesis

Because the $\alpha$-keto amide and 39-O-methyl groups are present on the rapamycin analog, the rapQONML genes are not involved in their biosynthesis. The remaining methyltransferase gene in the rapQONML deletion strain, 
Table 2. Selected NMR data for 16-O-desmethyl-27-desmethoxyrapamycin and rapamycin. ${ }^{\mathrm{a}}$

\begin{tabular}{|c|c|c|c|c|}
\hline Position & 16-O-desmethyl-27-des & nethoxyrapamycin & rapamycin ${ }^{b}$ & \\
\hline & ${ }^{1} \mathrm{H} \delta(\mathrm{ppm})$ & ${ }^{13} \mathrm{C} \delta(\mathrm{ppm})$ & ${ }^{1} \mathrm{H} \delta(\mathrm{ppm})$ & ${ }^{13} \mathrm{C} \delta(\mathrm{ppm})$ \\
\hline 1 & & 170.4 & & 169.2 \\
\hline 2 & 5.20 & 51.8 & 5.29 & 51.3 \\
\hline 8 & & 166.6 & & 166.8 \\
\hline 9 & & 194.8 & & 192.5 \\
\hline 10 & & 98.9 & & 98.5 \\
\hline 27 & $2.52(\mathrm{dd}, 17.5,3.0 \mathrm{~Hz})$ & 46.8 & 3.71 & 84.9 \\
\hline & $2.64(\mathrm{dd}, 17.5,9.0 \mathrm{~Hz})$ & & & \\
\hline 32 & & 208.7 & & 208.2 \\
\hline 39 & 2.93 & 84.4 & 2.93 & 84.4 \\
\hline 40 & 3.39 & 73.9 & 3.35 & 73.9 \\
\hline $16-\mathrm{OMe}$ & & & 3.13 & 55.8 \\
\hline 27-OMe & & & 3.34 & 59.5 \\
\hline 39-OMe & 3.41 & 56.4 & 3.41 & 56.5 \\
\hline
\end{tabular}

rapI, therefore must encode the enzyme responsible for methylating the 39-hydroxyl group on a rapamycin precursor. This is consistent with the observation that rapI is most closely related to $f k b M$ in the FK506 cluster, which has been shown to be required for methylation of the 31hydroxyl group of an FK506 precursor. It follows that the methyltransferases encoded by the $\operatorname{rap} Q$ and $\operatorname{rap} M$ genes must be responsible for methylation of the 16- and 27hydroxyl groups, although the precise specificity of these enzymes cannot be determined from the work reported here. The remaining $\mathrm{P} 450$ hydroxylase gene in the rapamycin cluster of the rap $Q O N M L$ deletion strain is rapJ, which therefore must encode the enzyme for hydroxylation of $\mathrm{C}-9$, consistent with its close homology to $f k b D$. Finally, one can infer that the rapN gene is responsible for hydroxylation at $\mathrm{C}-27$.

Under identical fermentation conditions, the parent strain produced about $20 \mathrm{mg} /$ liter of rapamycin, while KOS20-
001 produced about $10 \mathrm{mg} /$ liter of the analog. Because production was not dramatically reduced relative to the parent, the other post-PKS processing enzymes do not require a substrate that has already been modified at the 16 and 27 positions. Thus, either the 16 and 27 positions are the last to be modified, or the post-PKS modification enzymes recognize only a limited region of the molecule.

\section{Acknowledgments}

We thank Sally Ou for the 10 liter fermentation, Dr. HonG Fu for early analytical work, Dr. N. LOMOVSKAYA for advice with the phage system, DAVID H. HAWKE of PE Biosystems for high resolution mass spectrometry, and Prof. DAvID HoPwOOD for a critical reading of the manuscript.

\section{References}

1) Sehgal, S. N.; H. Baker \& C. Vezina: Rapamycin (AY- 
22,989), a new antifungal antibiotic. II. Fermentation, isolation and characterization. J. Antibiotics 28: 727 732,1975

2) Schwecke, T.; J. F. Aparicio, I. Molnar, A. Konig, L. E. Khaw, S. F. Haydock, M. Oliynyk, P. Caffrey, J. Cortes, J. B. Lester, G. A. Bohm, J. Staunton \& P. F. LEADLAY: The biosynthetic gene cluster for the polyketide immunosuppressant rapamycin. Proc. Natl. Acad. Sci. U.S.A. 92: 7839 7843, 1995

3) KATZ, L.: Manipulation of modular polyketide synthases. Chem. Rev. 97: 2557 2576, 1997

4) Aparicio, J. F.; I. Molnar, T. Schwecke, A. Konig, S. F. HaYDock, L. E. KhaW, J. Staunton \& P. F. Leadlay: Organization of the biosynthetic gene cluster for rapamycin in Streptomyces hygroscopicus: analysis of the enzymatic domains in the modular polyketide synthase. Gene 169: 9 16, 1996

5) Molnar, I.; J. F. Aparicio, S. F. Haydock, L. E. KhaW, T. Schwecke, A. Konig, J. Staunton \& P. F. Leadlay: Organisation of the biosynthetic gene cluster for rapamycin in Streptomyces hygroscopicus: analysis of genes flanking the polyketide synthase. Gene 169: 1 7, 1996

6) Khaw, L. E.; G. A. Bohm, S. Metcalfe, J. Staunton \& P. F. LEADLAY: Mutational biosynthesis of novel rapamycins by a strain of Streptomyces hygroscopicus NRRL 5491 disrupted in rapL, encoding a putative lysine cyclodeaminase. J. Bacteriol. 180: 809 814, 1998

7) Motamedi, H.; A. Shafiee, S. J. Cai, S. L. Streicher, B. H. ARISON \& R. R. Miller: Characterization of methyltransferase and hydroxylase genes involved in the biosynthesis of the immunosuppressants FK506 and FK520. J. Bacteriol. 178: 5243 5248, 1996

8) Shafiee, A.; H. Motamedi, F. J. Dumont, B. H. Arison \& R. R. Miller: Chemical and biological characterization of two FK506 analogs produced by targeted gene disruption in Streptomyces sp. MA6548. J.
Antibiotics 50: 418 423, 1997

9) Paiva, N. L.; A. L. Demain \& M. F. Roberts: Incorporation of acetate, propionate, and methionine into rapamycin by Streptomyces hygroscopicus. J. Nat. Prod. 54: $167 \sim 177,1991$

10) Reynolds, K. A. \& A. L. Demain: Rapamycin, FK506, and ascomycin-related compounds. In Biotechnology of Antibiotics, Ed., W. R. STROHL, pp. 497 520, M. Dekker, New York, 1997

11) Konig, A.; T. Schwecke, I. Molnar, G. A. Bohm, P. A. Lowden, J. Staunton \& P. F. Leadlay: The pipecolateincorporating enzyme for the biosynthesis of the immunosuppressant rapamycin-nucleotide sequence analysis, disruption and heterologous expression of rapP from Streptomyces hygroscopicus. Eur. J. Biochem. 247: 526 534, 1997

12) Denis, F. \& R. Brzezinski: An improved aminoglycoside resistance gene cassette for use in Gram-negative bacteria and Streptomyces. FEMS Microbiol. Lett. 65: $261 \sim 264,1991$

13) Hopwood, D. A.; M. J. Bibb, K. F. Chater, T. Kieser, C. J. Bruton, H. M. Kieser, D. J. Lydiate, C. P. SMith, J. M. WARD \& H. SCHREMPF: Genetic Manipulation of Streptomyces: A Laboratory Manual The John Innes Foundation, Norwich, UK, 1985

14) Lomovskaya, N.; L. Fonstein, X. Ruan, D. Stassi, L. KATZ \& C. R. Hutchinson: Gene disruption and replacement in the rapamycin-producing Streptomyces hygroscopicus strain ATCC 29253. Microbiology 143: 875 883, 1997

15) Mcalpine, J. B.; S. J. Swanson, M. Jackson \& D. N. WHITTERN: Revised NMR assignments for rapamycin. J. Antibiotics 44: 688 690, 1991

16) Findlay, J. A.; J. S. LiU, D. J. Burnell \& T. T. NAKASHIMA: The structure of demethoxyrapamycin. Can. J. Chem. 60: 2046 2047, 1982 